\title{
Editorial
}

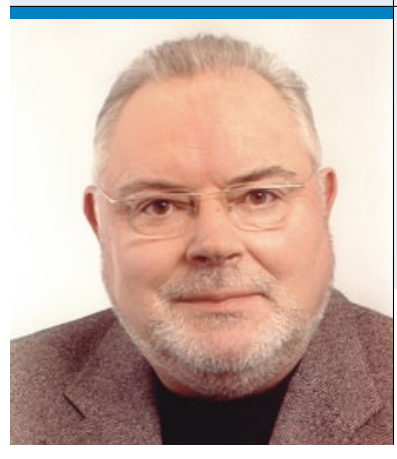

„Die neue EBM-Fassung lässt - trotz einiger Einschränkungen - manch positive Entwicklung erkennen."

Dr. med. Dieter Leithäuser

Chefredakteur und HNO-Arzt, Warburg

\section{Ein Schimmer am Horizont}

D

as Editorial der letzten Ausgabe hatte ich mit dem Zitat aus Goethes Osterspaziergang überschrieben: „....allein mir fehlt der Glaube!" $\mathrm{Zu}$ Beginn des neuen Jahres habe ich meine Meinung geändert und bin zum Shakespear'schen Hamlet gewechselt: „Es tut sich was im Staate Dänemark.“ Kommt jetzt endlich Bewegung in eine überfällige (EBM)-Szene? Im Original heißt es allerdings ,Something is rotten in the state of Denmark. "Hoffentlich gilt dies nicht für die neue EBM-Fassung, die am 1.1.12 wirksam wurde. Vieles darin sieht durchaus positiv aus, wenn auch mit unterschiedlichen Einschränkungen in manchen KV-Regionen. Während beispielsweise den HNO-Ärzten in Schleswig-Holstein erfreulicherweise $12,8 \%$ mehr zugesprochen werden, sind besonders bei KVen wie Nordrhein und der KV Westfalen-Lippe bisher keine substanziellen Honorarsteigerungen zu erkennen. Das darf nicht so bleiben.

Zwar wäre der Slogan „EBM HNO NEU“ übertrieben, aber neu aufgenommene Ziffern und vor allem die interessanten Zusatzpauschalen sollten ungeteilte Beachtung finden und mit entsprechend differenzierter ICD-Kodierung dokumentiert werden:

-Zusatzpauschale bei der Behandlung eines Patienten mit akuter, schwer stillbarer Nasenblutung (825 P.).

_Zusatzpauschale bei der Diagnostik des Tinnitus (435 P.).

- Nachsorge der op. Behandlung nach chronischer Sinusitis (235 P.), $10 \mathrm{x}$ im Behandlungsfall.

_Zusatzpauschale Nachsorge nach Tympanoplastik Typ II-V (235 P.), 1 x am Behandlungstag, 4 x im Behandlungsfall.

— Neuverordnung eines Hörgerätes (1325 P.), 1 x im Behandlungsfall.

- Nachuntersuchung nach Hörgeräteverordnung (1135 P.), 1 x im Behandlungsfall.

-Weitere Nachuntersuchung(en) nach Hörgeräteversorgung (980 P.). ab 3 Monate nach Verordnung, $2 \mathrm{x}$ im Krankheitsfall.
_ Koordination mit dem Hörgeräteakustiker (175 P.), $1 \mathrm{x}$ am Behandlungstag, $2 \mathrm{x}$ im Behandlungsfall.

_Zuschlag zur Hyposensibilisierungsspritze für jede weitere Injektion (200 P.), 4 x am Behandlungstag! Wichtig dabei ist, alle festgelegten Zeitintervalle einzuhalten, oder soll man besser sagen die festgefahrenen Zeiten:

1.Ein Behandlungsfall ist die Behandlung desselben Versicherten durch dieselbe Arztpraxis in einem Kalendervierteljahr zulasten derselben Krankenkasse.

2. Ein Krankheitsfall umfasst das aktuelle sowie die drei nachfolgenden Kalendervierteljahre, die der Berechnung der auf Krankheitsfaktoren bezogenen Gebührenordnungspositionen folgen.

Nun ist es für uns HNO-Kollegen an der Zeit diese wichtigen Veränderungen im EBM im Praxisalltag einzusetzen. Wir haben in der Vergangenheit genug Einschnitte hinnehmen und verdauen müssen. Wichtig finde ich jetzt eine lückenlose, differenzierte Dokumentation, auch wenn sie bürokratisch und zeitaufwendig erscheinen mag. Packen wir's an, es wird schon gelingen.

Gestatten Sie mir auch noch ein Wort zu einer bedauerlichen Entwicklung: Wie Sie vermutlich gelesen haben, gibt unsere geschätzte „Konkurrenz", die Zeitschrift HNO-kompakt auf. Bei uns kommt darüber sicher keine "klammheimliche Freude" auf, eher schon Bedauern, dass wirtschaftliche Zwänge gerade in einem so kleinen Fach wie der HNO-Heilkunde eine so große Rolle spielen müssen. Auch wenn HNONachrichten und HNO-kompakt teilweise als Rivalen gesehen wurden, so war thematisch doch immer Platz für beide Zeitschriften. Die HNO-Gemeinde ist nun um eine publizistische Stimme ärmer - schade!

Ihr
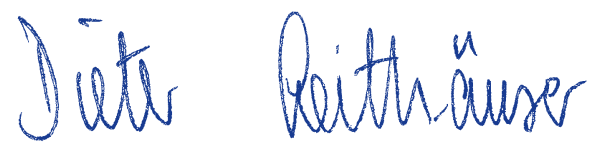